\title{
Adsorption of Cd(II) from acidic aqueous solutions by tourmaline as a novel material
}

\author{
WANG CuiPing*, WANG BaoLin, LIU JingTing, YU Li, SUN HongWen \& WU JiZhou \\ Key Laboratory of Pollution Processes and Environmental Criteria of the Ministry of Education, College of Environmental Science and \\ Engineering, Nankai University, Tianjin 300071, China
}

Received October 16, 2011; accepted March 30, 2012

\begin{abstract}
Batch experiments were conducted to investigate the behavior and mechanisms for the adsorption of Cd(II) from aqueous solutions by tourmaline under acidic conditions. The results indicated that the adsorption of $\mathrm{Cd}(\mathrm{II})$ significantly depend on the adsorption time, temperature, and the initial concentration of the metal ion. Furthermore, tourmaline had a very good adsorption capacity for $\mathrm{Cd}(\mathrm{II})$ in acidic, neutral and alkaline aqueous solutions. This good adsorption capacity is attributed to the observation that tourmaline can automatically adjust the $\mathrm{pH}$ values of acidic (except pH 2.0 and 3.0), neutral or alkaline aqueous solutions to 6.4. Specifically, the removal capacity for Cd(II) was higher at strongly acidic $\mathrm{pH}$ values (in contrast to industrial wastewater $\mathrm{pH}$ values) compared to that obtained for other types of adsorbents. Furthermore, the results obtained in this study showed good fits to the Langmuir and Freundlich adsorption isotherms. However, the Langmuir model fit better than the Freundlich model. The maximum uptake of $\mathrm{Cd}(\mathrm{II})$ by tourmaline was $31.77,33.11$ and $40.16 \mathrm{mg} / \mathrm{g}$ at $\mathrm{pH} 4.0$ at 15,25 and $35^{\circ} \mathrm{C}$, respectively. Therefore, tourmaline is an effective adsorbent for the removal of $\mathrm{Cd}(\mathrm{II})$ from acidic aqueous solutions. In addition, the kinetics for the $\mathrm{Cd}(\mathrm{II})$ adsorption by tourmaline closely followed the pseudo-second-order model. The thermodynamic parameters indicated that adsorption was feasible, spontaneous, and endothermic. Furthermore, the $\mathrm{pH}$ variation after adsorption, $\zeta$-potential, metal ions desorbed and released, and FT-IR analysis indicated that the physisorption and chemisorption mechanisms of tourmaline for heavy metals. These mechanisms included water that was automatically polarized by tourmaline, the ion exchange process, and electropolar adsorption. Among the mechanisms, the automatic polarization of water caused by tourmaline is a unique adsorption mechanism for tourmaline.
\end{abstract}

tourmaline, cadmium, acidic aqueous solutions, adsorption, mechanisms

Citation: Wang C P, Wang B L, Liu J T, et al. Adsorption of Cd(II) from acidic aqueous solutions by tourmaline as a novel material. Chin Sci Bull, 2012, 57: 3218-3225, doi: 10.1007/s11434-012-5341-6

With the increase in industrialization and urbanization, wastewater containing many heavy metals has been produced by electroplating, dyes, and the metallurgical and chemical industries. Furthermore, heavy metal pollution has become increasingly serious. Heavy metals have a negative impact on the environment because they are toxic to humans, animals, and plants, and they are not biodegradable. Therefore, heavy metals are prone to bioaccumulation in food chains, which results in a long-term toxic effect, even at low concentrations. Cadmium is one of the most dangerous heavy metals because of its presence in nature. Most of

*Corresponding author (email: wangcp@nankai.edu.cn) the cadmium that enters the body accumulates in the liver, kidney, pancreas and bones, which causes diseases such as anemia, hypertension, neuralgia, nephritis and secretion disorder [1]. Developing methods for effectively removing heavy metals from wastewater has become an important issue. Accordingly, a number of methods, including adsorption, chemical precipitation, ion exchange, and membrane technologies have been developed and implemented for removing heavy metal ions from different types of wastewater. However, the costs of removing heavy metal from wastewater using chemical precipitation, ion exchange, and membrane technologies are very high. Adsorption is a very effective and widely used method for removing heavy 
metals from water. In recent years, many natural adsorbents have been investigated for removing heavy metals from water. Different types of minerals, including zeolites [2], quartz [3], apatites [4], goethite [5], calcite [6], and dolomite [7] have been successfully utilized collectively and separately to remove heavy metal ions from aqueous solutions using adsorption techniques. However, when the above sorbents were used to remove heavy metals from acidic solutions, their maximum adsorption capacity was very low. Therefore, the development of a new material for treating acidic wastewater is an area of major concern for environmental science.

Tourmaline is a type of smart, functional ecological material, and it is also a green environmental protection material. Tourmaline is a type of complex borosilicate mineral and has a very complex chemical composition. The general chemical formula of tourmaline is expressed as $\mathrm{XY}_{3} \mathrm{Z}_{6}$ $\left(\mathrm{T}_{6} \mathrm{O}_{18}\right)\left(\mathrm{BO}_{3}\right)_{3} \mathrm{~V}_{3} \mathrm{~W}$, where $\mathrm{X}=\mathrm{Na}^{+}, \mathrm{K}^{+}, \mathrm{Ca}^{2+}$ or a vacancy; $\mathrm{Y}=\mathrm{Li}^{+}, \mathrm{Fe}^{2+}, \mathrm{Fe}^{3+}, \mathrm{Al}^{3+}, \mathrm{Mg}^{2+}, \mathrm{Cr}^{3+}, \mathrm{V}^{3+},\left(\mathrm{Ti}^{4+}\right) ; \mathrm{Z}=\mathrm{V}^{3+}, \mathrm{Fe}^{3+}$, $\mathrm{Cr}^{3+}, \mathrm{Al}^{3+}, \mathrm{Mg}^{2+}, \mathrm{Fe}^{3+} ; \mathrm{T}=\mathrm{Si}^{4+}, \mathrm{Al}^{3+},\left(\mathrm{B}^{3+}\right) ; \mathrm{B}=\mathrm{B}^{3+}, \mathrm{V}=$ $[\mathrm{O}(3)]=\mathrm{OH}^{-}, \mathrm{O}^{2-} ; \mathrm{W}=[\mathrm{O}(1)]=\mathrm{OH}^{-}, \mathrm{O}^{2-}, \mathrm{F}^{-}$and metal ions in parenthesis indicate minor or possible substitutions [8]. The variety of atom and ion species at three sites, $\mathrm{X}, \mathrm{Y}$ and $\mathrm{Z}$, in tourmaline permits a wide range of compositions and colors. Therefore, the unique properties of tourmaline, such as electrical, magnetic and calorific properties, are determined by its structure. Tourmaline adopts the trigonal space group $\mathrm{C}_{3 \mathrm{v}}-\mathrm{R} 3 \mathrm{~m}$. The crystal structure consists of $\left[\mathrm{Si}_{6} \mathrm{O}_{18}\right]$ complex tripartite rings, $\left[\mathrm{BO}_{3}\right]$ triangles, and $\mathrm{X}-\mathrm{O}_{5}(\mathrm{OH})$ triple octahedra. Within this structure, the corners of the six silicon-oxygen tetrahedra in the $\left[\mathrm{Si}_{6} \mathrm{O}_{18}\right]$ rings point to the same direction, which results in automatic polarization due to the presence of a permanent electric field [9]. Furthermore, the magnetic property of tourmaline is related to the presence of $\mathrm{Fe}^{2+}$ and $\mathrm{Fe}^{3+}$ in the $\mathrm{Y}$ site in its structure and is also likely to be related to the presence of $\mathrm{Fe}$ in the $\mathrm{Z}$ site and $\mathrm{Mn}$ in the $\mathrm{Y}$ and $\mathrm{Z}$ sites. In addition, it has been reported that tourmaline is capable of radiating far infrared energy, permanently releasing negative ions, producing an electrostatic field and releasing rare microelements [10]. However, there are few reports on the use of tourmaline in environmental applications. In recent years, the applied research for tourmaline has focused on applications such as purifying water and air, aquiculture, and health care. Of course, these studies have become a hot research topic [11-13]. In China, there have been a small number of reports on the adsorption of $\mathrm{Cu}^{2+}, \mathrm{Zn}^{2+}, \mathrm{Cr}^{6+}$, and $\mathrm{Pb}^{2+}$ ions onto tourmaline [14-18], but only one report presented a detailed study on the behavior and adsorption mechanism of $\mathrm{Pb}^{2+}$ ions from strongly acidic wastewater using tourmaline [19].

In the present study, we investigate the adsorption characteristics of $\mathrm{Cd}(\mathrm{II})$ onto tourmaline using kinetic, thermodynamic, and isothermal tests under acidic conditions. This study can provide a novel adsorbent and theoretical basis for controlling heavy metal pollution in acidic wastewater.

\section{Materials and methods}

\subsection{Experimental reagents and materials}

All chemicals, such as cadmium nitrate, sodium hydroxide and hydrochloric acid, that were used in this study were of analytical grade and provided by the Tianjin Regent Station (Tianjin, China).

Iron-rich black tourmaline with particle sizes of $800 \mathrm{~nm}$ was purchased from the Hongyan Mineral Products Co., Ltd, Tianjin city, China. The tourmaline was produced in the Xinjiang province, China. The compositional analysis was performed using an electron microprobe analyzer (EMPA) equipped with a Shimadzu 1600 electron microprobe and a four channel wavelength dispersive spectrometer (WDS). The chemical composition of the tourmaline with $800 \mathrm{~nm}$ sized particles was as follows: $\mathrm{SiO}_{2}, 36.75 \% ; \mathrm{Al}_{2} \mathrm{O}_{3}, 33.62 \%$; $\mathrm{Fe}_{2} \mathrm{O}_{3}, 12.19 \% ; \mathrm{TiO}_{2}, 0.57 \% ; \mathrm{B}_{2} \mathrm{O}_{3}, 9.78 \%$; $\mathrm{FeO}, 1.7 \%$; $\mathrm{CaO}, 0.4 \% ; \mathrm{MgO}, 4.76 \% ; \mathrm{K}_{2} \mathrm{O}, 0.14 \% ; \mathrm{Na}_{2} \mathrm{O}, 0.74 \% ; \mathrm{P}_{2} \mathrm{O}_{5}$, $0.19 \% ; \mathrm{H}_{2} \mathrm{O}^{+}, 1.0 \%$; and $\mathrm{MnO}, 0.21 \%$.

\subsection{Solution preparation}

Deionized distilled water $\left(\mathrm{DD}-\mathrm{H}_{2} \mathrm{O}\right)$ was used to prepare all solutions and suspensions. Stock solutions of $\mathrm{Cd}$ (II) metal at concentrations of $1 \mathrm{~g} / \mathrm{L}$ were prepared using the metal nitrate. The $1 \mathrm{~g} / \mathrm{L}$ stock solution was prepared by weighing $2.745 \mathrm{~g}$ of cadmium nitrate, then adding $10 \mathrm{~mL}$ of $1 \mathrm{~mol} / \mathrm{L}$ $\mathrm{HNO}_{3}$ and adjusting the volume to $1 \mathrm{~L}$ in a volumetric flask with DD- $\mathrm{H}_{2} \mathrm{O} .25,50,75,100,125,150,175$ and $200 \mathrm{~mL}$ samples of this stock were taken and set the volume to 500 $\mathrm{mL}$ in a volumetric flask with $\mathrm{DD}-\mathrm{H}_{2} \mathrm{O}$, respectively. Finally, the 50,100, 150, 200, 250, 300, 350 and $400 \mathrm{mg} / \mathrm{L}$ cadmium nitrate solutions were obtained. These stock solutions were stored in a refrigerator at $4^{\circ} \mathrm{C}$ to protect the solutions from light.

\subsection{Adsorption experiments}

Batch sorption experiments were conducted in acid-washed $50 \mathrm{~mL}$ plastic polypropylene centrifuge tubes, each of which contained $20 \mathrm{~mL}$ of the $100 \mathrm{mg} / \mathrm{L}$ multi-component solutions and tourmaline. The $\mathrm{pH}$ was adjusted using $1 \mathrm{~mol} / \mathrm{L}$ nitric acid and $1 \mathrm{~mol} / \mathrm{L}$ sodium hydroxide. To accurately control the temperature, the flasks for the batch adsorption experiments were placed into a thermostated container. After adsorption, the above adsorption systems were centrifuged at $3000 \mathrm{r} / \mathrm{min}$ for $15 \mathrm{~min}$, and then, $10 \mathrm{~mL}$ aliquots of each supernatant were filtered into acid-washed $15 \mathrm{~mL}$ plastic polypropylene centrifuge tubes by vacuum filtration through $0.22 \mu \mathrm{m}$ cellulose filter paper (Millipore Corp.). Afterwards, the residual concentrations of $\mathrm{Cd}(\mathrm{II})$ were determined using a WFX-210 atomic absorption spectrophotometer (Beijing, China). Metal solutions that did not contain sorbent served as controls. 


\subsection{Fourier transform infrared analysis}

Fourier transform infrared (FT-IR) spectra of the tourmaline both before and after $\mathrm{Cd}(\mathrm{II})$ binding were recorded using a Bruker Tensor 27 FT-IR spectrometer from 400 to 4000 $\mathrm{cm}^{-1}$ at a resolution of $4 \mathrm{~cm}^{-1}$. A background spectrum of $\mathrm{KBr}$ was recorded to eliminate contributions from the background, such as atmospheric $\mathrm{CO}_{2}$ and $\mathrm{H}_{2} \mathrm{O}$, which would contaminate the spectra. The samples were packed into a sample holder, their surfaces were smoothed with a glass slide, and they were immediately transferred to a diffuse reflectance cell, which was flushed with $\mathrm{N}_{2}$ for $10 \mathrm{~min}$ to remove water vapor and $\mathrm{CO}_{2}$.

\subsection{Adsorption kinetic models}

In this experiment, kinetic models were used to examine the experimental data. The Lagergren pseudo-first-order (eq. (1)) and pseudo-second-order models (eq. (2)) were used.

$$
\begin{aligned}
& 1 / Q_{t}=K_{1} /\left(Q_{\mathrm{m}} t\right)+1 / Q_{\mathrm{m}}, \\
& t / Q_{t}=1 /\left(K_{2} Q_{\mathrm{m}}{ }^{2}\right)+t / Q_{\mathrm{m}},
\end{aligned}
$$

where $Q_{t}$ and $Q_{\mathrm{m}}(\mathrm{mg} / \mathrm{g})$ are the metal concentrations at time $t$ and the maximum mass, respectively. The pseudo-firstorder constant $\left(K_{1}\right)$, pseudo-second-order constant $\left(K_{2}\right)$ and linear correlation coefficient $\left(R^{2}\right)$ were listed in Table 1 .

\subsection{Adsorption isotherm models}

To quantitatively explain the adsorption capacity of tourmaline for $\mathrm{Cd}(\mathrm{II})$, the equilibrium data were analyzed using the Langmuir (eq. (3)) and Freundlich (eq. (4)) models.

$$
\begin{gathered}
\frac{C_{\mathrm{e}}}{Q_{\mathrm{e}}}=\frac{1}{K_{\mathrm{L}} Q_{\mathrm{m}}}+\frac{C_{\mathrm{e}}}{Q_{\mathrm{m}}}, \\
\log Q_{\mathrm{e}}=\log K_{\mathrm{F}}+\frac{1}{n} \log C_{\mathrm{e}},
\end{gathered}
$$

where $Q_{\mathrm{m}}$ and $Q_{\mathrm{e}}(\mathrm{mg} / \mathrm{g})$ are the maximum mass and equilibrium mass of metal adsorption, respectively. $C_{\mathrm{e}}$ refers to the equilibrium metal concentrations in the tourmaline and aqueous phases. $K_{\mathrm{L}}(\mathrm{L} / \mathrm{mg})$ is the Langmuir isotherm parameter, and $K_{\mathrm{F}}$ is the Freundlich isotherm parameter. $n$ is a heterogeneity parameter of the adsorbent surface.

\section{Results and methods}

\subsection{Adsorption kinetics}

To determine the adsorption kinetics behavior for $\mathrm{Cd}(\mathrm{II})$ by tourmaline under acidic conditions, the adsorption studies were conducted at a temperature of $25^{\circ} \mathrm{C}$ at $\mathrm{pH} 4.0$ with an added adsorbent mass of $6 \mathrm{~g} / \mathrm{L}$ and a $\mathrm{Cd}(\mathrm{II})$ solution concentration of $100 \mathrm{mg} / \mathrm{L}$. The adsorption time was 5, 15, 30 min, 1, 3, 6, 12, 24 and $48 \mathrm{~h}$, and its effects on the adsorption of $\mathrm{Cd}(\mathrm{II})$ by tourmaline are illustrated in Figure 1. The complete removal of $\mathrm{Cd}(\mathrm{II})$ ions increased rapidly during the first $360 \mathrm{~min}$; thereafter, the adsorption percentage increased slowly and reached equilibrium at $1440 \mathrm{~min}$. This behavior was due to the decrease of adsorption sites on the tourmaline, which gradually interacted with the metal ions. In this study, $59.10 \%$ of $\mathrm{Cd}(\mathrm{II})$ was adsorbed onto tourmaline under acidic conditions of $\mathrm{pH} 4.0$ with an adsorption time of $2880 \mathrm{~min}$. This result was attributed to the large number of vacant active sites on the tourmaline surface at early time points; $\mathrm{Cd}(\mathrm{II})$ can be adsorbed by tourmaline rapidly through electrostatic adsorption. When the adsorption time was prolonged, the adsorption sites on the tourmaline surface were decreased, which resulted in the reduced percentage of adsorption.

To evaluate the mechanisms of adsorption and the potential rate controlling step, kinetic models were used to test experimental data. The Lagergren pseudo-first-order (eq. (1)) and pseudo-second-order models (eq. (2)) were used. The pseudo-first-order constant $\left(K_{1}\right)$, pseudo-second-order constant $\left(K_{2}\right)$, and linear correlation coefficient $\left(R^{2}\right)$ are listed in Table 1. The correlation coefficients for the first-order model were low, and the calculated $Q_{\mathrm{e}}$ values obtained from the first-order kinetic model are not reasonable values. However, the correlation coefficient for the second-order kinetic model are greater than 0.994, and the calculated $Q_{\mathrm{e}}$ values obtained from the second-order kinetic model nearly agree with the experimental $Q_{\mathrm{e}}$ values for the Cd(II) adsorption. Therefore, the pseudo-second-order model appears to be the best for describing the $\mathrm{Cd}(\mathrm{II})$ adsorption kinetics. Normally, the Lagergren pseudo-first-order model (eq. (1)) is only suitable for describing the initial stage of adsorption

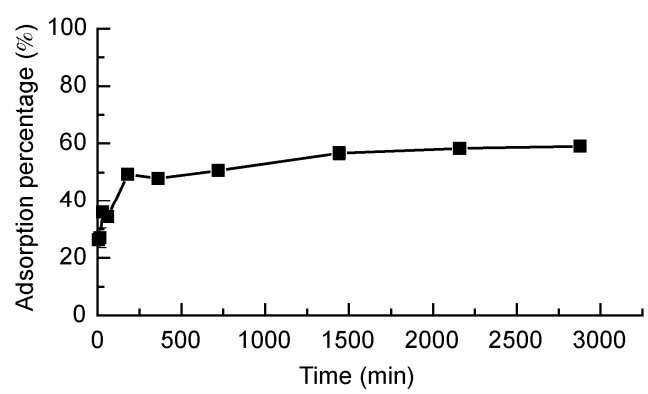

Figure 1 Kinetic study of adsorption of $\mathrm{Cd}(\mathrm{II})$ ions by tourmaline: $\mathrm{pH}$ 4.0 ; adsorbent, $0.12 \mathrm{~g}$ of tourmaline $/ 20 \mathrm{~mL} ; \mathrm{Cd}^{2+}, 100 \mathrm{mg} / \mathrm{L} ; 25^{\circ} \mathrm{C}$.

Table 1 Pseudo-first-order and Pseudo-second-order adsorption rate constants of Cd(II) on tourmaline, calculated and experimental $Q_{\mathrm{e}}$

\begin{tabular}{lcccc}
\hline \multicolumn{1}{c}{ Models } & Model equations & $K_{1}$ or $K_{2}$ & $Q_{\mathrm{m}, \text { cal }}(\mathrm{mg} / \mathrm{g})$ & $Q_{\mathrm{m}, \mathrm{exp}}(\mathrm{mg} / \mathrm{g})$ \\
\hline Pseudo-first-order & $1 / Q_{t}=0.6275 / t+0.1218$ & $4.70\left(\mathrm{~min}^{-1}\right)$ & 7.94 & 0.6581 \\
Pseudo-second-order & $t / Q_{t}=0.0989 t+4.2162$ & $0.0029\left(\mathrm{~g} \mathrm{mg}^{-1} \mathrm{~min}^{-1}\right)$ & 10.2 & 13.05 \\
\hline
\end{tabular}


kinetics; consequently, this model cannot accurately describe accurately the entire adsorption process [20]. However, the pseudo-second-order model can describe the entire adsorption process, including external diffusion, surface adsorption and internal diffusion [21]; therefore, this model can accurately reflect the adsorption mechanisms of $\mathrm{Cd}(\mathrm{II})$ onto tourmaline. When the pseudo-second-order model is the best fit for the experimental data, the sorption mechanism involves chemisorption [22].

\section{$2.2 \mathrm{pH}$ effects}

The effect of $\mathrm{pH}$ on the adsorption of $\mathrm{Cd}(\mathrm{II})$ ions using tourmaline was investigated. The experiments were performed at different initial $\mathrm{pH}$ values at $25^{\circ} \mathrm{C}$. To avoid precipitation of the metal ions, all experimental $\mathrm{pH}$ were determined based on heavy metal solubility product constant, $K_{\text {sp. }}$ The maximum precipitation of $\mathrm{Cd}(\mathrm{II})$ occurred at $\mathrm{pH}$ 8.4 with an initial concentration of $100 \mathrm{mg} / \mathrm{L}$. Therefore, to prevent any precipitation occurring before the sorption experiments, the $\mathrm{pH}$ was controlled between 2.0-8.0. The initial concentration of heavy metal and the adsorbent dose were fixed at $100 \mathrm{mg} / \mathrm{L}$ and $4 \mathrm{~g} / \mathrm{L}$, respectively. The equilibrium time was $24 \mathrm{~h}$. The equilibrium concentration of each metal ion was determined at the different $\mathrm{pH}$ values. The results are graphically represented in Figure 2. It is evident from Figure 2(a) that when the initial $\mathrm{pH}$ of the suspension was less than 4.0 , the removal capacity was $12.0 \%$ for $\mathrm{Cd}(\mathrm{II})$ (Figure 2(a)); when the initial $\mathrm{pH}$ ranged from 4.0 to 6.0, the adsorption percentage for $\mathrm{Cd}(\mathrm{II})$ ranged from $31 \%$ to $49 \%$; when the initial $\mathrm{pH}$ was neutral or alkaline, the
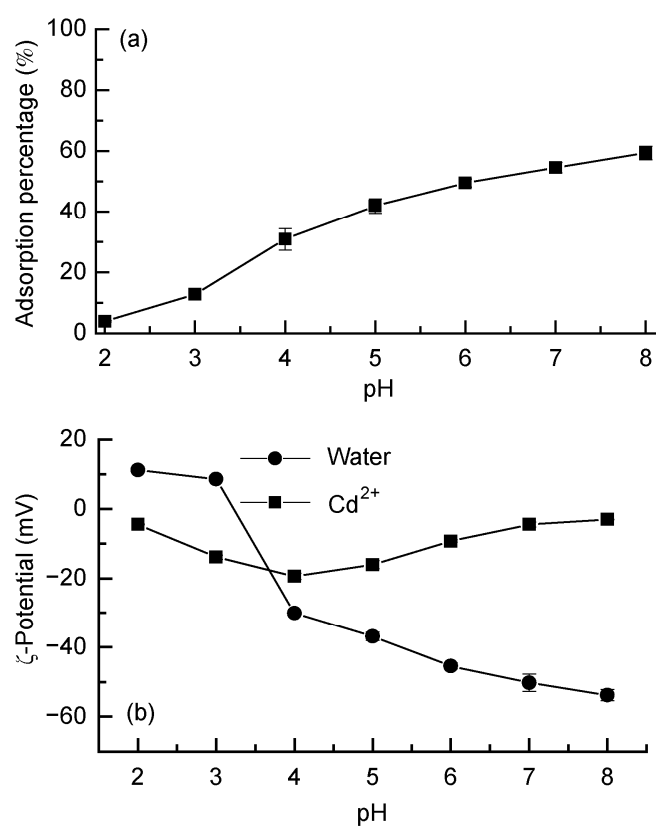

Figure 2 (a) $\mathrm{pH}$ effects on adsorption of $\mathrm{Cd}(\mathrm{II})$ ion by tourmaline: adsorbent, $0.4 \mathrm{~g}$ of tourmaline $/ 100 \mathrm{~mL} ; \mathrm{Cd}^{2+}, 100 \mathrm{mg} / \mathrm{L} ; T, 25^{\circ} \mathrm{C}$. (b) Variation of $\zeta$-potential of tourmaline in water and solutions containing 100 $\mathrm{mg} / \mathrm{L} \mathrm{Cd}(\mathrm{II})$ ion at $25^{\circ} \mathrm{C}$, respectively. adsorption percentage ranged from $55 \%$ to $59 \%$. Therefore, tourmaline has a good adsorption capacity for high concentrations of $\mathrm{Cd}(\mathrm{II})$ under acidic, neutral and alkaline conditions. Specifically, the removal capacity for $\mathrm{Cd}(\mathrm{II})$ was higher under strongly acidic $\mathrm{pH}$ values (in contrast to industrial wastewater $\mathrm{pH}$ values) compared to that obtained for other types of adsorbents that have been used in the past, such as zeolites [2,23], quartz [3], calcite [24], dolomite [25], kaolinite [26], and different types of clays [27].

The $\mathrm{pH}$ influenced the adsorption process for metal ions. This observation was attributed to the surface charge of tourmaline, which could be modified by changing the $\mathrm{pH}$ of the solution. It can be observed from Figure 2(b) that the $\zeta$-potential of tourmaline in water became more negative with increasing $\mathrm{pH}$. In addition, at different $\mathrm{pH}$ values, the extent of the variation of the $\zeta$-potential of the heavy metal adsorbed by tourmaline was different. At lower $\mathrm{pH}$ values $(<4.0)$, the active sites of the adsorbent are less available for the metal ions because of the protonation of the active sites under higher $\mathrm{H}^{+}$concentrations, which results in less $\mathrm{Cd}(\mathrm{II})$ being adsorbed by tourmaline. At moderate $\mathrm{pH}$ values (e.g., 4.0-6.0), linked $\mathrm{H}^{+}$is released from the active sites and the adsorbed amounts of the metal ions are increased. Furthermore, the $\zeta$-potential of the $\mathrm{Cd}(\mathrm{II})$ adsorbed by tourmaline became less negative than that of tourmaline in water (Figure 2(b)), which indicates that the tourmaline surfaces were covered with heavy metal ions. In this $\mathrm{pH}$ range, it was proposed that the ion exchange and electropolar adsorption processes are the major mechanisms for removing single metal ions from the solution [28]. At $\mathrm{pH}$ values greater than 6.0, the $\zeta$-potentials of the tourmaline adsorbed $\mathrm{Cd}$ (II) became slightly negative. It was suggested that both ion exchange and aqueous metal hydroxide formation (not precipitation) may become significant mechanisms for the metal removal process [28].

\subsection{Initial concentration and temperature effects}

To obtain the adsorption isotherms and investigate the adsorption thermodynamics, the effect of the initial concentration on the metal ion adsorption capacities of tourmaline was determined by varying the initial concentration of the metal ion solutions. The operating conditions were as follows: the sorbent dose was fixed at $2 \mathrm{~g} / \mathrm{L}$ and the initial concentrations of the $\mathrm{Cd}$ (II) solutions ranged from 50 to 400 $\mathrm{mg} / \mathrm{L}$ at an initial $\mathrm{pH}$ 4.0. The experiments were performed at 15,25 , and $35^{\circ} \mathrm{C}$. The results are shown in Figure 3.

From Figure 3, it is seen that the amount of $\mathrm{Cd}(\mathrm{II})$ adsorbed per gram of tourmaline gradually increased with increasing initial concentration of the metal ion solutions. When the initial solution was at a low concentration, the ratio between the number of ions and the number of adsorptive sites available is small; consequently, the adsorption depends on the initial concentration. Therefore, as the concentration of ions increases, the adsorption also increases. 


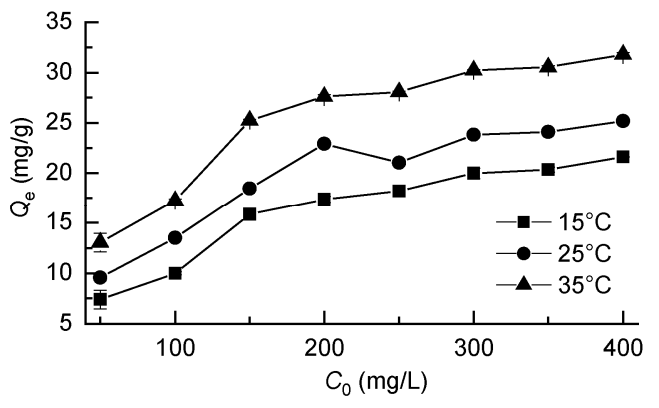

Figure 3 Initial concentration and temperature effects on adsorption of $\mathrm{Cd}(\mathrm{II})$ ion by tourmaline: adsorbent, $0.2 \mathrm{~g}$ of tourmaline/100 mL; $\mathrm{pH} 4.0$.

At high ion concentrations, each unit mass of adsorbent is subjected to a larger number of ions, which gradually fill the sites. Therefore, the amount of Cd(II) adsorbed per gram of tourmaline was higher.

It was observed that the adsorption of $\mathrm{Cd}(\mathrm{II})$ increased with increasing temperature. Because adsorption is an endothermic process, it would be expected that an increase in temperature would help to activate the adsorption sites of the adsorbent. In addition, an increase in temperature involved an increased mobility of the metal ions, which resulted in the metal ions having sufficient energy for interacting with the adsorption sites of the adsorbent. Therefore, the adsorptive capacity of the adsorbent was enhanced [29].

\subsection{Adsorption isotherms}

The two most commonly employed models are the Langmuir and Freundlich isotherms. The Langmuir isotherms of $\mathrm{Cd}(\mathrm{II})$ at different temperatures are shown in Figure 4, and the corresponding parameters are presented in Table 2. The results indicated that that the adsorption of $\mathrm{Cd}(\mathrm{II})$ on tourmaline followed the Langmuir isotherm model very well based on the values of $R^{2}(0.97-0.99)$ (Table 2); they also fit the Freundlich isotherm model with the values of $R^{2}$ (0.93-0.96), but better than the Langmuir isotherm model in general (Table 2).

The Freundlich isotherm parameter was listed in Table 2. The magnitude of $1 / n$ quantifies the favorability of adsorption and the degree of heterogeneity of the tourmaline surface. The values of $1 / n$ in this study were observed to be less than 1 , which indicates that the adsorption for $\mathrm{Cd}(\mathrm{II})$ was favorable.

As shown in Table 2 , at 15,25 , and $35^{\circ} \mathrm{C}$, the values of the Langmuir constant, $K_{\mathrm{L}}$, were $0.0065,0.0098$ and 0.131
$\mathrm{L} / \mathrm{mg}$ for $\mathrm{Cd}(\mathrm{II})$. The maximum adsorption capacity $\left(Q_{\mathrm{m}}\right)$ were $31.77,33.11$ and $40.16 \mathrm{mg} / \mathrm{g}$ for Cd(II) (Table 2) at an initial solution $\mathrm{pH} 4.0$, respectively, while the temperature varied from 15 to $35^{\circ} \mathrm{C}$. A comparison of the $Q_{\mathrm{m}}$ determined in the present study with that obtained for other types of adsorbents used in the past, such as zeolites [2,23], quartz [3], calcite [24], dolomite [25], kaolinite [26], and different types of clays [27] was made. The removal capacities for $\mathrm{Cd}(\mathrm{II})$ using tourmaline in the present study were compared to those of other natural adsorbents, as shown in Table 3. It was observed that tourmaline exhibits very high removal capacities for the $\mathrm{Cd}$ (II) ion under acidic conditions, which suggests that the adsorption capacity of tourmaline was very high. Therefore, tourmaline is an effective adsorbent for the removal of heavy metals from wastewater.

\subsection{Thermodynamics of adsorption}

The thermodynamic parameters, such as the Gibbs free energy change $\left(\Delta G^{\circ}\right)$, enthalpy change $\left(\Delta H^{\circ}\right)$, and entropy change $\left(\Delta S^{\circ}\right)$, for the adsorption of $\mathrm{Cd}(\mathrm{II})$ were evaluated using the following equations:

$$
\begin{gathered}
-\Delta G^{\circ}=2.303 R T \log K, \\
\Delta G^{\circ}=\Delta H^{\circ}-T \Delta S^{\circ},
\end{gathered}
$$

where $\Delta G^{\circ}$ is the change in free energy $(\mathrm{kJ} / \mathrm{mol}), \Delta H^{\circ}$ is the change in enthalpy $(\mathrm{kJ} / \mathrm{mol}), \Delta S^{\circ}$ is the change in entropy $(\mathrm{kJ} / \mathrm{mol}), T$ is the absolute temperature in Kelvin, $R$ is the gas constant $\left(8.314 \times 10^{-3}\right)$ and $K$ is the thermodynamic equilibrium constant. The values of $\Delta H^{\circ}$ and $\Delta S^{\circ}$ were calculated from the slope and intercept of the plot between $\ln K$ versus $1 / T$.

The thermodynamic parameters for the adsorption of $\mathrm{Cd}(\mathrm{II})$ are presented in Table 4 . The positive values of $\Delta H^{\circ}$ indicated the endothermic nature of the adsorption of $\mathrm{Cd}(\mathrm{II})$ on tourmaline. Therefore, the metal ion uptake increased with increasing temperature. In addition, enthalpy change data are typically used for distinguishing between physical adsorption and chemical adsorption. When the enthalpy change is greater than $60 \mathrm{~kJ} / \mathrm{mol}$, the adsorption is typically associated with chemical adsorption, whereas when the heat of adsorption is less than $40 \mathrm{~kJ} / \mathrm{mol}$, the adsorption should be associated with physical adsorption [30]. These experimental enthalpy changes are less than $40 \mathrm{~kJ} / \mathrm{mol}$, which implies that physisorption dominates the adsorption of metal ions onto tourmaline. The negative $\Delta G^{\circ}$ values were predicated to be $-15.77,-16.78$ and $-17.37 \mathrm{~kJ} / \mathrm{mol}$ for the

\begin{tabular}{|c|c|c|c|c|c|c|}
\hline \multirow{2}{*}{ Temperature $\left({ }^{\circ} \mathrm{C}\right)$} & \multicolumn{3}{|c|}{ Freundlich model } & \multicolumn{3}{|c|}{ Langmuir model } \\
\hline & $K_{\mathrm{F}}$ & $1 / n$ & $R^{2}$ & $Q_{\mathrm{m}}(\mathrm{mg} / \mathrm{g})$ & $K_{\mathrm{L}}(\mathrm{L} / \mathrm{mg})$ & $R^{2}$ \\
\hline 15 & 0.9753 & 0.5568 & 0.9634 & 31.77 & 0.0065 & 0.9750 \\
\hline 25 & 1.2773 & 0.4749 & 0.9359 & 33.11 & 0.0098 & 0.9786 \\
\hline 35 & 1.5900 & 0.4326 & 0.9491 & 40.16 & 0.0131 & 0.9909 \\
\hline
\end{tabular}

Table 2 Different model parameters for adsorption of Cd(II) by tourmaline at different temperatures 


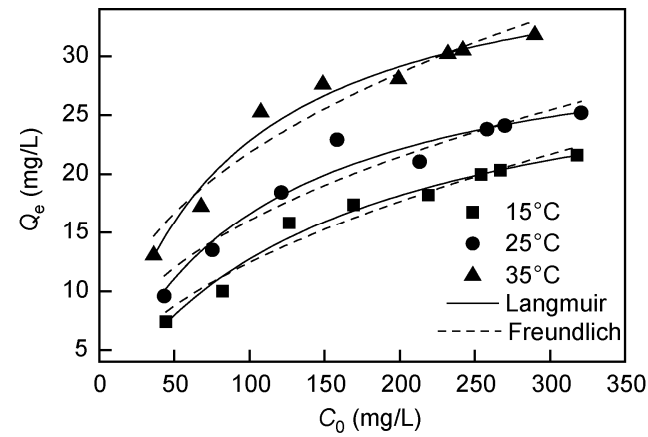

Figure 4 Adsorption isotherms of $\mathrm{Cd}(\mathrm{II})$ ion by tourmaline at different temperatures.

Table 3 Comparison of Cd(II) removal by natural adsorbents (unit of Langmuir capacity is $\mathrm{mg} / \mathrm{g}$ )

\begin{tabular}{lccc}
\hline Adsorbents & $\mathrm{Cd}(\mathrm{II})$ ion & $\mathrm{pH}$ & References \\
\hline Zeolite & 0.1 & No listed & {$[2]$} \\
Quartz & 9.41 & 6.8 & {$[3]$} \\
Clinoptilolite & 4.22 & No listed & {$[23]$} \\
Calcite & 18.52 & $5.0-6.0$ & {$[24]$} \\
Dolomite & 1.02 & & {$[25]$} \\
Kaolinite & 9.9 & $6.0-8.0$ & {$[26]$} \\
Red mud & 10.60 & 6.0 & {$[27]$} \\
Tourmaline & 40.16 & 4.0 & This study \\
\hline
\end{tabular}

Table 4 Thermodynamic parameters of $\mathrm{Cd}^{2+}$ ion adsorption on tourmaline

\begin{tabular}{ccccc}
\hline Metal ions & $T\left({ }^{\circ} \mathrm{C}\right)$ & $\Delta G^{\circ}(\mathrm{kJ} / \mathrm{mol})$ & $\Delta H^{\circ}(\mathrm{kJ} / \mathrm{mol})$ & $\Delta S^{\mathrm{o}}(\mathrm{J} / \mathrm{mol})$ \\
\hline \multirow{3}{*}{$\mathrm{Cd}^{2+}$} & 15 & -15.77 & 24.69 & 140.5 \\
& 25 & -16.78 & 24.69 & 139.2 \\
& 35 & -17.37 & 24.69 & 136.6 \\
\hline
\end{tabular}

adsorption of $\mathrm{Cd}(\mathrm{II})$ ion, which indicated that the adsorption of metal ions on tourmaline is a feasible and spontaneous process and that energy input from outside of the system is required. Generally, the Gibbs free energy change (0 -20 $\mathrm{kJ} / \mathrm{mol}$ ) for physisorption processes are lower than that for chemisorption (-80 -100 kJ/mol) processes [31]. In the present study, the negative $\Delta G^{\circ}$ values were between 0 to $-20 \mathrm{~kJ} / \mathrm{mol}$ for the adsorption of $\mathrm{Cd}(\mathrm{II})$, which indicated that the adsorption of the metal ion onto tourmaline is a physisorption process. The positive values of $\Delta S^{\circ}$ indicated that the degrees of freedom increase at the solid-solution interface during the adsorption of the metal ion by tourmaline. Simultaneously, in this study, $\Delta S^{\circ}$ was greater than zero. This observation was attributed to the fact that the $\Delta S^{\circ}$ value depends on the two actions of the dissociation of hydrated ions and the adsorption of free state ions in the adsorption process. The dissociation of hydrated ions can induce increases in $\Delta S^{\circ}$, whereas the adsorption of free-state ions can result in decreases in $\Delta S^{\circ}$. When a hydrated cadmium (II) ion dissociates, it can dissociate more than one water molecule. Specifically, the number of dissociating water molecules was higher than that of adsorbing $\mathrm{Cd}(\mathrm{II})$ ions, which resulted in the positive value of $\Delta S^{\circ}$ [32].

\subsection{Adsorption mechanisms}

(1) Water polarized by tourmaline. The $\mathrm{pH}$ value during the $\mathrm{Cd}$ (II) adsorption process was measured, and the results are presented in Figure 5. It was observed that when at an initial metal solution $\mathrm{pH} 4.0$, the $\mathrm{pH}$ quickly increased to 5.25 within $5 \mathrm{~min}$; thereafter, the $\mathrm{pH}$ increased to 6.0 within $30 \mathrm{~min}$ and reached equilibrium at $180 \mathrm{~min}$. Furthermore, at different initial $\mathrm{pH}$ values of the solution, the $\mathrm{pH}$ values were measured when the $\mathrm{Cd}(\mathrm{II})$ adsorption by tourmaline reached equilibrium. The results are presented in Figure 6. The overall trend indicated an increase in $\mathrm{pH}$, with the final $\mathrm{pH}$ values being higher than the initial levels ranging from $\mathrm{pH} 2.0$ to 6.0 , whereas a decrease in $\mathrm{pH}$ was observed, with the final $\mathrm{pH}$ values being lower than the initial $\mathrm{pH}$ values of 7.0 and 8.0 (Figure 6). Additionally, the final $\mathrm{pH}$ tended to be approximately 6.0 when the initial $\mathrm{pH}$ ranged from 4.0 to 8.0. Therefore, our study confirms that tourmaline can automatically adjust the solution $\mathrm{pH}$ because of its spontaneous and permanent poles [9]. When tourmaline was crushed to smaller particle sizes, a large number of mineral cations (such as magnesium, calcium, and sodium) were exposed on the crystal surface along different directions of the crystal fracture. When the tourmaline was then added to aqueous solutions, water was automatically polarized by the tourmaline powder, and hydrogen ions from the polar water molecules pulled these cations from the crystal surface into the water. Finally, the loss of cations on the tourmaline surface increased their negative charge, which resulted in more $\mathrm{Cd}(\mathrm{II})$ being adsorbed by tourmaline. This process also caused the $\mathrm{pH}$ value to adjust in the solutions that contained added tourmaline [19]. This adsorption mechanism of

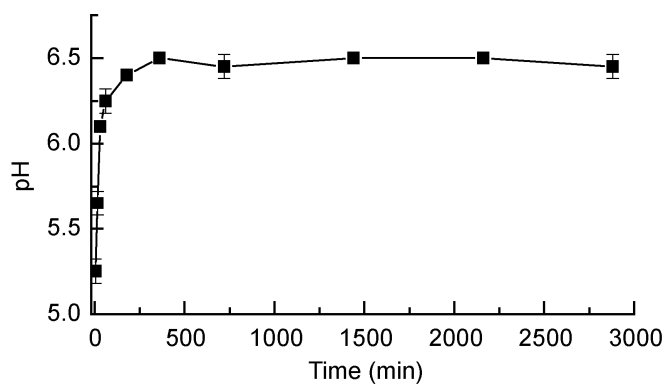

Figure $5 \mathrm{pH}$ change of solution during the adsorption of $\mathrm{Cd}(\mathrm{II})$ ion by tourmaline.

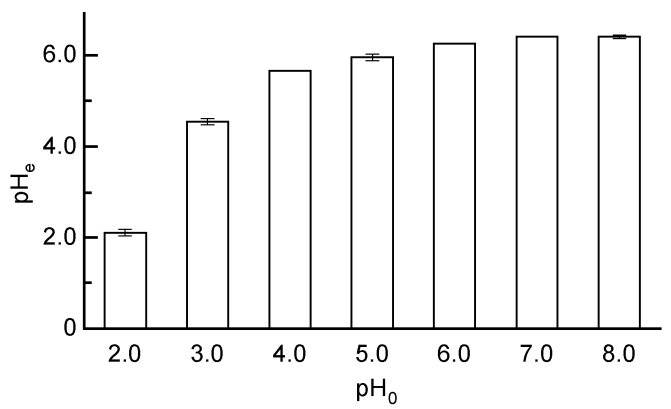

Figure $6 \mathrm{pH}$ change of solution during adsorption equilibrium of $\mathrm{Cd}(\mathrm{II})$ ion by tourmaline at different initial $\mathrm{pHs}$ of solution. 
tourmaline is unique; furthermore, it is obviously different from that of other minerals.

(2) $\zeta$-Potential measurements. To fully understand the other mechanisms that occur during heavy metal adsorption onto tourmaline, the $\zeta$-potentials of the adsorption system were also measured during the study of the isotherm study system. The measured $\zeta$-potentials of tourmaline were -32 $\mathrm{mV}$ at $15^{\circ} \mathrm{C},-30 \mathrm{mV}$ at $25^{\circ} \mathrm{C}$, and $2-9 \mathrm{mV}$ at $3{ }^{\circ} \mathrm{C}$. In the presence of $\mathrm{Cd}(\mathrm{II})$, the $\zeta$-potential values increased from -24 to $-13 \mathrm{mV}$ at $15^{\circ} \mathrm{C}$, from -23 to $-8 \mathrm{mV}$ at $25^{\circ} \mathrm{C}$, and from -19 to $-4 \mathrm{mV}$ at $35^{\circ} \mathrm{C}$, at all concentrations (Figure 7). Compared with the $\zeta$-potential of tourmaline, changes in $\zeta$-potential can be explained by mechanisms occurring between the tourmaline particle and a $\mathrm{Cd}(\mathrm{II})$ ion. Furthermore, the trend coincides with the adsorption mass of $\mathrm{Cd}(\mathrm{II})$ at different temperatures, which is noted in the adsorption isotherms. Therefore, it can be said that the adsorption proceeds through the electrostatic adsorption mechanisms.

(3) Metal ions desorbed and release. To determine whether other mechanisms occurred between tourmaline and the heavy metals, the desorbed ion concentrations (such as $\mathrm{K}^{+}, \mathrm{Ca}^{2+}$ and $\mathrm{Mg}^{2+}$ ) from the tourmaline were synchronously measured using ion chromatography during the adsorption process in the isotherm studies on the $\mathrm{Cd}(\mathrm{II})$ ion. Figure 8 indicates that the total masses of the released $\mathrm{Ca}^{2+}$, $\mathrm{Mg}^{2+}$, and $\mathrm{K}^{+}$were low with respect to the masses of the $\mathrm{Cd}(\mathrm{II})$ ions adsorbed by tourmaline. It was observed in Figure 8 that there were good linear relationships between the release of the total cations $\left(R^{2}=0.6010,0.9738\right.$, and 0.8918$)$ into solutions and that the $\mathrm{Cd}(\mathrm{II})$ ion adsorbed onto tourmaline over heavy metal ion concentrations ranging from 50 to

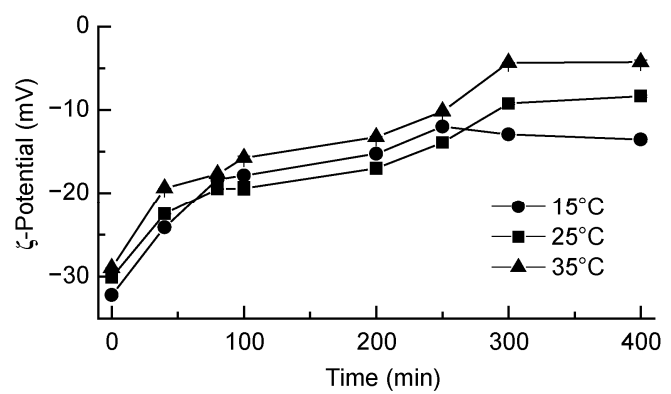

Figure 7 ל-Potential change during the process of $\mathrm{Cd}(\mathrm{II})$ ion adsorption at different initial concentrations at different temperatures.

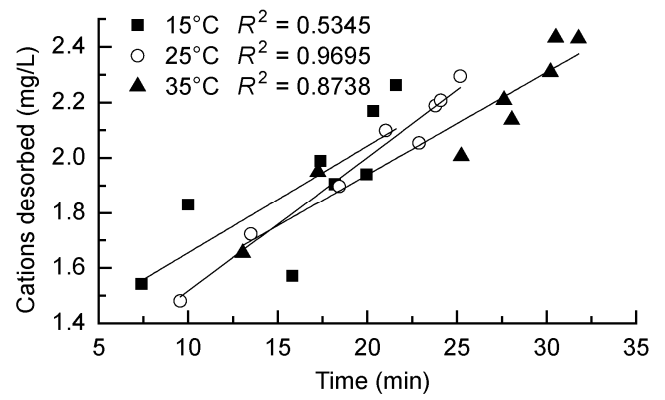

Figure 8 Total amount of $\mathrm{K}^{+}, \mathrm{Mg}^{2+}$ and $\mathrm{Ca}^{2+}$ cations released into solution versus amount of heavy metal ions adsorbed at different temperature.
$400 \mathrm{mg} / \mathrm{L}$. These positive correlations confirmed that cation exchange was involved during the removal of heavy metals from acidic solutions. However, the ion exchange mechanism for heavy metals adsorbed onto tourmaline has never been demonstrated.

(4) FT-IR analysis. FT-IR spectroscopy can not only effectively characterize the surface functional groups in tourmaline but also explore the changes in these functional groups in the presence of metal ions. The tourmalines and their adsorption for $\mathrm{Cd}(\mathrm{II})$ at different $\mathrm{pH}$ values at $25^{\circ} \mathrm{C}$ were analyzed using FT-IR spectrophotometry. The comparison of the spectra presented in Figure 9 indicated significant differences in the intensities of the bands between 1161 and $682 \mathrm{~cm}^{-1}$ for tourmaline and its adsorption for $\mathrm{Cd}(\mathrm{II})$ ions at $\mathrm{pH} 2.0,3.0$ and 4.0. Noticeable increases in the broad bands (i.e., $1650,1161-682 \mathrm{~cm}^{-1}$ ), especially at $1161,985,967$ and $682 \mathrm{~cm}^{-1}$ were observed after the tourmaline reacted with the aqueous $\mathrm{Cd}(\mathrm{II})$ ion compared to the spectra of tourmaline. The signals at $1650 \mathrm{~cm}^{-1}$ resulted from the presence of tourmaline-water vibrations. The increases in the broad bands at $1161-682 \mathrm{~cm}^{-1}$ were due to the internal $\mathrm{Si}-\mathrm{O}-\mathrm{Si}$ and $\mathrm{Al}-\mathrm{O}-\mathrm{Si}$ bridge vibrations in the tetrahedral or alumino- and silico-oxygen bridges and pseudolattice vibrations $[19,33,34]$. The change in the intensity of the bands in the above ranges can also be an indication of the presence of heavy metals in the tourmaline structure. Therefore, the incorporation of heavy metals into the tourmaline structure changed the degree of ring deformation, which resulted in changes in the signal intensities. This change was attributed to heavy metal bonding through electropolar adsorption and ion exchange due to the mass of cations released from the particle surface. This result supported the notion that physisorption and chemisorption were involved in the absorption of heavy metals by tourmaline.

\section{Conclusions}

This study demonstrated the effectiveness of tourmaline for removing metal ions from acidic, neutral and alkaline aqueous solutions. Specifically, the removal capacity for

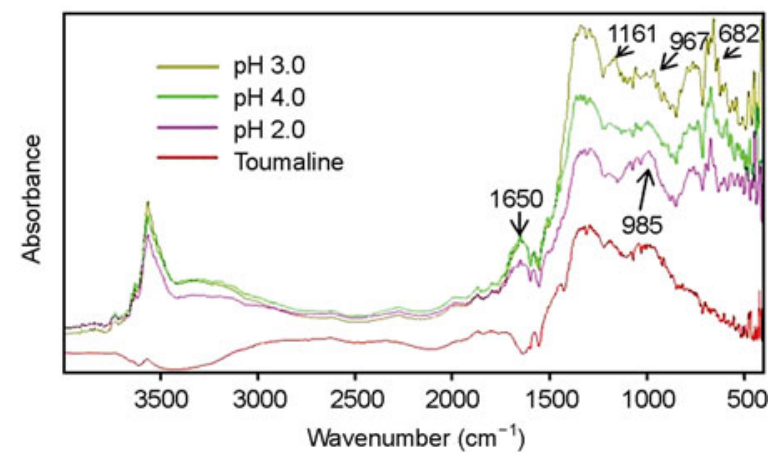

Figure 9 FT-IR spectra of tourmaline before and after interaction with $\mathrm{Cd}$ (II) ion at initial aqueous $\mathrm{pH} 2.0,3.0$ and 4.0 at $25^{\circ} \mathrm{C}$, respectively. 
$\mathrm{Cd}(\mathrm{II})$ was higher at strongly acidic $\mathrm{pH}$ values (in contrast to industrial wastewater $\mathrm{pH}$ values) compared to that obtained for other types of adsorbents. The maximum mass of Cd(II) adsorbed, evaluated using a Langmuir model, was $31.77,33.11$ and $40.16 \mathrm{mg} / \mathrm{g}$ on tourmaline at $\mathrm{pH} 4.0$ at 15 , 25 and $35^{\circ} \mathrm{C}$, respectively. Therefore, the adsorption mass increased with increasing temperature. The kinetics data presented a good correlation with the pseudo-second-order model, which indicated that chemisorption was involved during the absorption of heavy metal by tourmaline. Meanwhile, the thermodynamic parameters and $\Delta G^{\circ}$ ranged from 0 to $-20 \mathrm{~kJ} / \mathrm{mol}$, which indicated that the adsorption of heavy metals was feasible, spontaneous, and endothermic, and that physisorption was involved during the adsorption process. Therefore, mechanisms of tourmaline for $\mathrm{Cd}(\mathrm{II})$ were involved in physisorption and chemisorption. Furthermore, the FT-IR analysis confirmed that the physisorption and chemisorption mechanisms included water that was automatically polarized by tourmaline, the ion exchange process, and electropolar adsorption. Among these mechanisms, the automatic polarization of water by tourmaline is a unique adsorption mechanism for tourmaline. In general, tourmaline was an effective adsorbent for the removal of heavy metals from wastewater. Tourmaline should be developed as a new material for the removal of pollutants from the environment

This work was supported by the National Natural Science Foundation of China (20907024) and the Fundamental Research Funds for the Central Universities.

1 Meleki A, Zazoli M A, Shokrzadeh M. Investigation of cadmium content in Iranian rice (Oryza Sativa): Its weekly intake. J Appl Sci Environ Manag, 2007, 11: 101-105

2 Apiratikul $\mathrm{R}$, Pavasant $\mathrm{P}$. Sorption of $\mathrm{Cu}^{2+}, \mathrm{Cd}^{2+}$, and $\mathrm{Pb}^{2+}$ using modified zeolite from coal fly ash. Chem Eng J, 2008, 144: 245-258

3 AsçI Y, Nurbas M, AçIkel Y S. Investigation of sorption/desorption equilibria of heavy metal ions on/from quartz using rhamnolipid biosurfactant. J Environ Manag, 2010, 91: 724-731

4 Chen X, Wright J V, Conca J L, et al. Effects of pH on heavy metal sorption on mineral apatite. Environ Sci Technol, 1997, 3: 624-631

5 Buerge-Weirich D, Hari R, Xue H, et al. Adsorption of $\mathrm{Cu}, \mathrm{Cd}$, and $\mathrm{Ni}$ on goethite in the presence of natural groundwater ligands. Environ Sci Technol, 2002, 36: 328-336

6 Davis J A, Fuller C C, Cook A D. A model for trace metal sorption processes at the calcite surface: Adsorption of $\mathrm{Cd}^{2+}$ and subsequent solid solution formation. Geochim Cosmochim Acta, 1987, 51: 1477-1490

7 Pehlivan E, Özkan A M, Dinc S, et al. Adsorption of $\mathrm{Cu}^{2+}$ and $\mathrm{Pb}^{2+}$ on dolomite powder. J Hazard Mater, 2009, 167: 1044-1049

8 Fuat Y. Tourmaline: Software package for tourmaline, tourmalinerich rocks and related ore deposits. Comput Geosci, 1997, 23: 47-59

9 Kubo N T. Tourmaline group crystals reaction with water. Ferroelectrics, 1992, 137: 13-31

10 Ruan D, Zhang L N, Zhang Z J, et al. Structure and properties of regenerated cellulose/tourmaline nanocrystal composite films. Polym
Phys: Part B, 2004, 42: 367-373

11 Nakamura T, Kubo T. The tourmaline group crystals reaction with water. Ferroelectrics, 1992, 137: 13-31

12 Xia M S. Study on application of tourmaline in the water treatment of recirculating aquaculture system. Dissertation for the Doctoral Degree. Zhejiang: Zhejiang University, 2005. 41-47

13 Yoshio M. Physiology effects wearing AP fiber cloth special tourmaline crystal powder. J Int Soc Life Inform Sci, 2001, 19: 69-72

14 Jiang K, Sun T H, Sun L N, et al. Adsorption characteristics of copper, lead, zinc and cadmium ions by tourmaline. J Environ Sci, 2006, 18: 1221-1225

15 Tang Y H, Wu R H, Zhang X H. The mechanism of applying tourmaline to purifying $\mathrm{Cu}^{2+}$-doped waste water (in Chinese). Aata Petrologica et Mineralogica, 2002, 21: 192-195

16 Liu F, Jiang K. Adsorption of $\mathrm{Zn}^{2+}$ from wastewater by tourmaline (in Chinese). Liaoning Urban Rural Environ Sci Technol, 2004, 24 : 32-34

$17 \mathrm{Zu} \mathrm{E} \mathrm{D,} \mathrm{Duan} \mathrm{Y} \mathrm{B,} \mathrm{Zhao} \mathrm{K} \mathrm{Y,} \mathrm{et} \mathrm{al.} \mathrm{Tourmaline} \mathrm{to} \mathrm{purifying}$ $\mathrm{Cr}^{6+}$-doped waste water (in Chinese). Mater Prot, 2005, 38: 49-51

18 Zhou Z Y, Guan J F, Li W, et al. The experimental study of adsorption of $\mathrm{Pb}^{2+}$ by tourmaline power (in Chinese). Jiangsu Environ Sci Technol, 2006, 19: 22-24

19 Wang C P, Wu J Z, Sun H W, et al. Adsorption of $\mathrm{Pb}$ (II) ion from aqueous solutions by tourmaline as a novel adsorbent. Ind Eng Chem Res, 2011, 50: 8515-8523

20 Ding S M, Feng X H, Wang Y T, et al. Equilibrium and adsorption kinetics of analysis of crosslinked chitosan porous microspheres of dye (in Chinese). J Anal Sci, 2005, 21: 129

21 Li C L, Yue Q Y, Li Y. Adsorption and desorption of Zinc (II) and cadmium (II) onillite (in Chinese). J Shandong Univ, 2009, 44: 9

22 Ho Y S, McKay G. Pseudo-second order model for sorption processes. Process Biochem, 1999, 34: 451-465

23 Sprynskyy M, Buszewski B, Terzyk A P, et al. Study of the selection mechanism of heavy metal $\left(\mathrm{Pb}^{2+}, \mathrm{Cu}^{2+}, \mathrm{Ni}^{2+}\right.$, and $\left.\mathrm{Cd}^{2+}\right)$ adsorption on clinoptilolite. J Colloid Interf Sci, 2006, 304: 21-28

24 Yavuz Ö, Guzel R, Aydin F, et al. Ziyadanogullari removal of cadmium and lead from aqueous solution by calcite. Polish J Environ Stud, 2007, 3: 467-471

25 Cheung C W, Porter J, Mckay G. Sorption kinetic analysis for the removal of the cadmium ions from effluents using Bone Char. Wat Res, 2001, 35: 605-612

26 Rao K S, Mohapatra M, Anand S, et al. Review on cadmium removal from aqueous solutions. Int J Eng Sci Technol, 2010, 2: 81-103

27 Sahu R C, Patel R, Ray B C. Adsorption of Zn(II) on activated red mud: Neutralized by $\mathrm{CO}_{2}$. Desalination, 2011, 266: 93-97

28 Üçer A, Uyanik A, Aygün Ş F. Adsorption of Cu(II), Cd(II), Zn(II), $\mathrm{Mn}$ (II) and Fe(III) ions by tannic acid immobilised activated carbon. Sep Purif Technol, 2006, 47: 113-118

29 Yu G M, Chen Y X. Biosorption of heavy metal from solution by tea waste: A review (in Chinese). Chin J Appl Ecol, 2010, 21: 505-513

30 Feng Y J, Zhang Z H, Gao P, et al. Adsorption behavior of EE2 (17 $\alpha$ ethinylestradiol) onto the inactivated sewage sluge: Kinetics, thermodynamics and influence factors. J Hazard Mater, 2010, 175: 970-976

31 Nollet $H$, Roels $M$, Lutgen $\mathrm{P}$, et al. Removal of PCBs from wastewater using fly ash. Chemosphere, 2003, 53: 655-665

32 Hao Y L, Fan F H, Liu Z M. Adsorption thermodynamic of $\mathrm{Cu}^{2+}$ on palygorskite clay (in Chinese). Acta Mineralogica Sinica, 2011, 31: 113-117

33 Mozgawa W. The influence of some heavy metals cations on the FTIR spectra of zeolites. J Mol Struct, 2000, 555: 299-304

34 Mozgawa W, Król M, Bajda T. Application of IR spectra in the studies of heavy metal cations immobilization on natural sorbents. J Mol Struct, 2009, 924-926: 427-433

Open Access This article is distributed under the terms of the Creative Commons Attribution License which permits any use, distribution, and reproduction in any medium, provided the original author(s) and source are credited. 